\title{
The value of shock index in prediction of cardiogenic shock developed during primary percutaneous coronary intervention
}

\author{
Zhonghai Wei ${ }^{* \dagger} \mathbb{D}$, Jian $\mathrm{Bai}^{\dagger}$, Qing Dai ${ }^{\dagger}$, Han Wu, Shuaihua Qiao, Biao Xu and Lian Wang ${ }^{*}$
}

\begin{abstract}
Background: Shock index(SI) is a conventional predictive marker for haemodynamic state. Its breakpoint varies by different conditions according to previous studies. The current study was performed to evaluate the capability of SI in prediction of cardiogenic shock(CS) developed during primary percutaneous coronary intervention (pPCI).

Methods: Total 870 patients of ST segment elevation myocardial infarction(STEMI) who were haemodynamic stable before $\mathrm{pPCl}$ were involved in the study. In this cohort, 625 consecutive patients composed analysis series and 245 consecutive patients composed validation series. Multivariate regression analysis was used to evaluate whether SI was a significant predictor of developed CS and Hosmer-Lemeshow test was used to assess the goodness of model fitness. Receiver-operating characteristics (ROC) analysis was used to compare the predictive capability of SI with other predictors. The sensitivity, specificity, accuracy, positive and negative predictive values of SI at different cutoff values was compared to identify a best breakpoint.

Results: In the analysis series, SI and Killips classification were identified as independent predictors. ROC analysis demonstrated the diagnostic capability of SI was superior to pre-procedural systolic blood pressure(SBP) or heart rate(HR) alone ( 0.8113 vs $0.7582, P=0.04$ and 0.8113 vs $0.7111, P<0.001)$. The diagnostic capability of $S$ I was equivalent to that of combination of SBP, HR and Killips claasification $(0.8133$ vs $0.8137, P=0.97)$. SI had a high specificity and low sensitivity. When the cutoff value was set at 0.93 , the positive predictive value, negative predictive value and diagnostic accuracy was $42.6 \%, 95.1 \%$ and $87.4 \%$ respectively. In validation series, the area under ROC curve was 0.8245 , which was similar to that in the analysis series. The positive predictive value, negative predictive value and diagnostic accuracy at the cutoff value of 0.93 was $53.8 \%, 93.2 \%$ and $88.9 \%$ respectively.
\end{abstract}

Conclusions: SI has a high predictive accuracy for developing CS during PPCI in STEMI patients. It is an excellent exclusion diagnosis index rather than confirmative diagnosis index.

Keywords: Shock index, Myocardial infarction, Cardiogenic shock, Reperfusion

\footnotetext{
*Correspondence: weizhnjjs@yeah.net; wanglianglyy@163.com

${ }^{\dagger}$ Zhonghai Wei, Jian Bai and Qing Dai contributed equally to this work.

Department of Cardiology, Drum Tower Hospital, Medical School of Nanjing

University, 321 Zhongshan Road, Nanjing 210008, Jiangsu Province, China
}

(c) The Author(s). 2018 Open Access This article is distributed under the terms of the Creative Commons Attribution 4.0 International License (http://creativecommons.org/licenses/by/4.0/), which permits unrestricted use, distribution, and reproduction in any medium, provided you give appropriate credit to the original author(s) and the source, provide a link to the Creative Commons license, and indicate if changes were made. The Creative Commons Public Domain Dedication waiver (http://creativecommons.org/publicdomain/zero/1.0/) applies to the data made available in this article, unless otherwise stated. 


\section{Background}

In the past three decades, the in-hospital and 1-year mortality of ST segment elevation myocardial infarction (STEMI) have been remarkably decreased due to timely revascularization [1]. However, the worsening of cardiac function after STEMI is still rising despite of optimal reperfusion and pharmacological therapy. The infarct-related heart failure will no doubt increase the long-term comorbidity and mortality, which may counterbalance the benefits from the timely reperfusion. Previous studies have revealed that approximate $50 \%$ of final infarct myocardium caused by reperfusion injury (RI) $[2,3]$. RI is therefore regarded as the leading cause of infarct size extension after blood flow recovery of infarct-related artery (IRA), which could possibly lead to cardiogenic shock (CS) during primary percutaneous coronary intervention (pPCI). It has been reported that patients of STEMI complicated with CS have 30-day or in-hospital mortality as high as nearly 50\% [4-7]. Hence, those stable patients of STEMI but probably developing to CS during pPCI should be identified in advance and it may provide the target patients to doctors to take measures for ease of RI.

Shock index (SI) is a marker assessing the haemodynamic state, which is calculated as heart rate (HR) divided by systolic blood pressure (SBP) [8]. Patients with elevated SI, even with normal blood pressure and heart rate, should be paid more attention for the high risk of shock. In the acute coronary syndrome (ACS) or STEMI patients cohort, SI has been proven the independent predictor of long-term major adverse cardiac events (MACE) or mortality [9-11]. Nevertheless, there are few studies on the efficacy of this marker in prediction of developing CS during emergency reperfusion. The current study was aimed to evaluate the predictive capability of CS developed during pPCI in the cohort of STEMI.

\section{Methods}

\section{Study population}

The study cohort was retrieved from the database of our center. The including criteria was as follows: (1) the patients were diagnosed STEMI; (2)there was no cardiogenic shock when admitted in emergency room; (3) the patients accepted PCI after emergency angiography. The exclusion criteria was as follows: (1)the patients presented cardiogenic shock when arrived emergency room;(2) the patients rejected emergency angiography; (3) the patients did not need emergency revascularization or need emergency coronary artery bypass graft (CABG) surgery; (4)the patients were deployed prophylactic IABP before revascularization.

From January 2010 to May 2017, total 1250 STEMI patients were admitted in our hospital. 250 patients were excluded because they did not accepted emergency PCI due to over the time window of emergency revascularization. 59 patients were excluded due to cardiogenic shock when admitted in emergency room. 37 patients were excluded for sake of prophylactic use of IABP. 23 patients were excluded because of referral to emergency CABG or referral to elected procedure. 11 patients were excluded due to refusal of emergency angiography. Therefore, the remaining 870 patients were eligible for the study cohort. The study population consisted of 2 series: 1 analysis series (625 consecutive patients for analysis and identification of predictive capability) and 1 validation series (245 consecutive patients for validation the predictive capability).

\section{Procedure details}

All the patients with acute chest pain in emergency room accepted ECG within $10 \mathrm{~min}$. STEMI was defined as new onset of ST segment elevation at the J point in at least 2 contiguous leads of more than $2 \mathrm{~mm}$ in men or more than $1.5 \mathrm{~mm}$ in women in V2 and V3 lead and/or of more than $1 \mathrm{~mm}$ in other leads. The presentation of new left bundle branch block was considered equivalent to STEMI [12]. Cardiogenic shock was defined that the systolic blood pressure of the patients is below $90 \mathrm{mmHg}$ more than $30 \mathrm{~min}$ or the inotropic agents are needed to maintain the systolic blood pressure above $90 \mathrm{mmHg}$ accompanied with pulmonary congestion and/or peripheral perfusion impairment [13].

The patients ready to accept primary PCI were administered a loading dose of aspirin $300 \mathrm{mg}$ and ticagrelor $180 \mathrm{mg}$ before the procedure. Clopidogrel $600 \mathrm{mg}$ was given if ticagrelor was contraindicated or unavailable. After a radial or femoral artery puncture, a $6 \mathrm{~F}$ sheath was inserted. Heparin was administered at a dose of 70-100 IU/kg, while tirofiban, urokinase or argatroban were used if necessary. Thrombus aspiration catheter was used if it was considered high burden of thrombus under angiography. After blood flow recovery of IRA, the stent was deployed immediately or delayed according to the discretion of coronary lesions and interventionists' experience. If CS occurred after the reperfusion of IRA, rescue IABP support was transfemorally placed preferentially. If the patients were not suitable for IABP, inotropic agents were alternative. All of the procedures were accomplished by experienced and qualified interventionists.

\section{Statistics}

Continuous normally distributed variables were shown as mean \pm standard deviation (mean $\pm \mathrm{SD}$ ) and were compared using T-test between two groups. While those that were not normally distributed were presented as median $(M)$ and interquartile range (IQR) 
Table 1 Characteristic of patients cohort

\begin{tabular}{|c|c|c|c|}
\hline & Non-Shock $(n=769)$ & Developed Shock $(n=101)$ & $P$ value \\
\hline Age,year[M(IQR)] & $64(55-74)$ & 63(55-73) & 0.52 \\
\hline Male sex,n(\%) & $610(79.3)$ & $76(75.6)$ & 0.35 \\
\hline Anterior myocardial infarction,n(\%) & $389(50.6)$ & $58(57.6)$ & 0.2 \\
\hline Hypertension,n(\%) & $505(65.7)$ & $69(68.8)$ & 0.60 \\
\hline Diabetes,n(\%) & $215(28.0)$ & $34(33.3)$ & 0.23 \\
\hline Prior Stroke,n(\%) & $101(13.1)$ & $30(30.3)$ & $<0.001$ \\
\hline Hyperlipidemia,n(\%) & $64(9.7)$ & $9(9.1)$ & 0.84 \\
\hline Smoke,n(\%) & $450(58.5)$ & $53(52.1)$ & 0.25 \\
\hline Prior myocardial infarction, n(\%) & 73(9.53) & 8(7.98) & 0.61 \\
\hline Creatinine, $\mu \mathrm{mol} / \mathrm{L}[\mathrm{M}(\mathrm{IQR})]$ & $72(62-87)$ & $69(60-81)$ & 0.22 \\
\hline$E F, \%[M(I Q R)]$ & $47(41-50)$ & $44(40-48)$ & 0.03 \\
\hline Triglyceride, mmol/L[M(IQR)] & $1.38(1.00-2.05)$ & $1.39(0.90-2.10)$ & 0.72 \\
\hline Cholesterol, mmol/L[M(IQR)] & $4.28(3.63-4.98)$ & $4.49(3.83-4.88)$ & 0.46 \\
\hline LDL-C, mmol/L[M(IQR)] & $2.31(1.84-2.80)$ & $2.29(1.91-2.79)$ & 0.93 \\
\hline $\mathrm{HDL}-\mathrm{C}, \mathrm{mmol} / \mathrm{L}[\mathrm{M}(\mathrm{IQR})]$ & $0.93(0.76-1.14)$ & $0.91(0.77-1.11)$ & 0.79 \\
\hline Pre-procedure SBP, mmHg[M(IQR)] & 123(112-138) & 104(96-108) & $<0.001$ \\
\hline Pre-procedure HR, bpm[M(IQR)] & $79(69-89)$ & $91(82-100)$ & 0.008 \\
\hline Total ischemic time, $\min [\mathrm{M}(\mathrm{IQR})]$ & $342(234-610)$ & $360(267-713)$ & 0.26 \\
\hline Killips class I//II, n(\%) & $185(24.0)$ & $30(28.7)$ & 0.50 \\
\hline Double vessel disease, $n(\%)$ & $310(40.3)$ & 34(33.3) & 0.20 \\
\hline Triple vessel disease, n(\%) & 235(30.6) & $40(39.4)$ & 0.07 \\
\hline \multicolumn{4}{|l|}{ IRA } \\
\hline$L A D, n(\%)$ & $389(50.6)$ & $58(57.6)$ & 0.20 \\
\hline LCX/OM, n(\%) & $123(16)$ & $1(0.99)$ & $<0.001$ \\
\hline $\mathrm{RCA}, \mathrm{n}(\%)$ & 195(25.4) & $43(42.4)$ & $<0.001$ \\
\hline PDA/PL, n(\%) & $65(8.5)$ & 0 & - \\
\hline PTCA, n(\%) & $12(1.51)$ & 0 & - \\
\hline \multicolumn{4}{|l|}{ Stents } \\
\hline Sirolimus, n(\%) & $481(62.6)$ & $58(57.6)$ & 0.32 \\
\hline Everolimus, n(\%) & $231(30.1)$ & $30(30.3)$ & 0.95 \\
\hline Zotarolimus, n(\%) & $155(20.1)$ & $24(24.2)$ & 0.40 \\
\hline Paclitaxel, n(\%) & $6(0.76)$ & 0 & - \\
\hline \multicolumn{4}{|l|}{ Mediction } \\
\hline Aspirin, $n(\%)$ & $769(100)$ & $101(100 \%)$ & 1.00 \\
\hline Clopidogrel, n(\%) & $516(67.1)$ & $64(63.4)$ & 0.45 \\
\hline Ticagrelor, n(\%) & 253(32.9) & $37(36.6)$ & 0.45 \\
\hline ACEI/ARB, n(\%) & $511(66.5)$ & $64(63.6)$ & 0.54 \\
\hline$\beta$-blocker, n(\%) & 606(78.8) & $70(69.4)$ & $<0.001$ \\
\hline Spironolactone, n(\%) & $442(57.5)$ & $63(62.7)$ & 0.35 \\
\hline Diuretics, n(\%) & $359(46.7)$ & $55(54.5)$ & 0.14 \\
\hline Statin, n(\%) & 767(99.8) & 100(99.6) & 0.31 \\
\hline
\end{tabular}

EF ejection fraction, $L D L-C$ low density lipoprotein cholesterol, $H D L-C$ high density lipoprotein cholesterol, SBP systolic blood pressure, $H R$ heart rate, IRA infarct related artery, $L A D$ left anterior descending branch, $L C X$ left circumflex branch, $O M$ obtuse marginal branch, $R C A$ right coronary artery, PDA posterior descending artery, $P L$ posterior branch of left venticule, $A C E I$ angiotensin converting enzyme inhibitor, $A R B$ angiotensin receptor blocker 
Table 2 Univariate regression analysis for the risk factors

\begin{tabular}{|c|c|c|c|c|}
\hline Variables & OR & SE & $P$ value & $95 \% \mathrm{Cl}$ \\
\hline Age & 1.00 & 0.01 & 0.57 & {$[0.991 .03]$} \\
\hline Female sex & 1.14 & 0.34 & 0.65 & {$[0.642 .04]$} \\
\hline Pre-Procedural SBP & 0.94 & 0.01 & $<0.01$ & {$\left[\begin{array}{lll}0.92 & 0.96\end{array}\right]$} \\
\hline Pre-Procedural HR & 1.05 & 0.01 & $<0.01$ & {$\left[\begin{array}{ll}1.03 & 1.06\end{array}\right]$} \\
\hline Total ischemic duration (per $1 \mathrm{~h}$ change) & 1.01 & 0.01 & 0.51 & {$[0.98$ 1.02] } \\
\hline \multicolumn{5}{|l|}{ Killips classification } \\
\hline Killips $=2$ vs $=1$ & 2.45 & 0.67 & 0.001 & [1.43 4.19] \\
\hline Killips $=3$ vs $=1$ & 6.20 & 3.44 & 0.001 & {$\left[\begin{array}{ll}2.09 & 18.4\end{array}\right]$} \\
\hline Multiple vessel disease & 1.44 & 0.39 & 0.18 & {$[0.852 .43]$} \\
\hline Extensive anterior $\mathrm{Ml}$ & 0.89 & 0.26 & 0.69 & {$\left[\begin{array}{lll}0.50 & 1.58\end{array}\right]$} \\
\hline Prior Ml & 0.96 & 0.73 & 0.95 & {$[0.22$ 4.25] } \\
\hline Prior hypertension & 0.61 & 0.15 & 0.05 & {$\left[\begin{array}{lll}0.37 & 1.00\end{array}\right]$} \\
\hline Prior diabetes & 0.72 & 0.22 & 0.28 & {$\left[\begin{array}{lll}0.40 & 1.30\end{array}\right]$} \\
\hline Prior stroke & 1.64 & 0.53 & 0.13 & {$\left[\begin{array}{lll}0.87 & 3.10\end{array}\right]$} \\
\hline Prior dyslipidemia & 1.06 & 0.45 & 0.89 & [0.46 2.44] \\
\hline Smoking & 0.96 & 0.24 & 0.88 & [0.59 1.58] \\
\hline Serum creatinine & 1.00 & 0.01 & 0.58 & {$\left[\begin{array}{ll}0.99 & 1.01\end{array}\right]$} \\
\hline
\end{tabular}

$S B P$ systolic blood pressure, $H R$ heart rate, $M I$ myocardial infarction

and compared using Wilcoxon rank-sum test between two groups. Categorical variables were shown as frequencies and percentages and were compared with $x^{2}$ test or Fisher exact test. In the regression analysis, the following variables in the analysis series were set in the univariate regression analysis initially: age, gender, pre-procedural systolic blood pressure(SBP), pre-procedural heart rate(HR), Killips classification, total ischemic duration, multiple vessel disease, extensive anterior myocardial infarction(MI), infarct related artery(IRA), hypertension, diabetes, dyslipidemia, prior MI, prior stroke, smoking hobby, serum creatinine. The variables significant in univariate analysis were subsequently set in the multivariate analysis. The variables were selected using backwards method. The regression models were calibrated with Hosmer-Lemeshow $\chi^{2}$ test for the goodness of fit. Thereafter, the significant covariates were tested for the accuracy with receiver-operating characteristics (ROC) analysis. The area under curve (AUC) was calculated to compare the diagnostic capability of the predictors. Specificity, sensitivity and Youden index (specificity+sensitivity-1) were calculated for identification of a reasonable cutoff value. In the validation series, the predictors were analyzed with ROC in order to identify the predictive value. The statistical analysis was performed by Stata version 12.0 (StataCop., College Station, Texus, USA). All the tests were 2 sided. Values of $P<0.05$ were considered statistically significant.

\section{Results}

\section{Characteristics of study population}

Total 870 patients were valid for the current study. The median age was $65 \mathrm{y}$ with interquartile range of $55 \mathrm{y}-74 \mathrm{y}$. There were 686 male patients $(78.9 \%)$ and 184 female patients(21.1\%). 769 patients were hemodynamic stable during pPCI(Non Shock Group), whereas 101 patients had developed CS during the procedure(Developed Shock Group). Compared with Developed Shock Group, Non Shock Group had lower proportion patients with prior stroke $(P<0.001)$, higher EF value $(P=0.03)$, higher pre-procedural $\operatorname{SBP}(P<0.001)$ and lower pre-procedural $\operatorname{HR}(P=0.008)$. Furthermore, more patients had left circumflex branch(LCX) or obtuse marginal branch(OM) as IRA and less patients had right coronary artery(RCA) as IRA in the Non Shock Group $(\mathrm{P}<0.001)$. As regard to pharmacological therapy, there were more patients taking $\beta$-blocker in Non Shock Group in comparison with that in

Table 3 Multivariate regression analysis for risk factors

\begin{tabular}{lllll}
\hline Variables & OR & SE & $P$ value & $95 \%$ Cl \\
\hline Pre-Procedural SBP & 0.95 & 0.01 & $<0.01$ & {$\left[\begin{array}{lll}0.93 & 0.96\end{array}\right]$} \\
Pre-Procedural HR & 1.05 & 0.01 & $<0.01$ & {$\left[\begin{array}{ll}1.03 & 1.07\end{array}\right]$} \\
Killips classification & & & & \\
$\quad$ Killips $=2$ vs $=1$ & 2.34 & 0.76 & 0.01 & {$\left[\begin{array}{lll}1.24 & 4.44\end{array}\right]$} \\
$\quad$ Killips $=3$ vs $=1$ & 5.30 & 2.86 & 0.02 & {$\left[\begin{array}{lll}1.27 & 22.1\end{array}\right]$}
\end{tabular}

SBP systolic blood pressure, $H R$ heart rate 

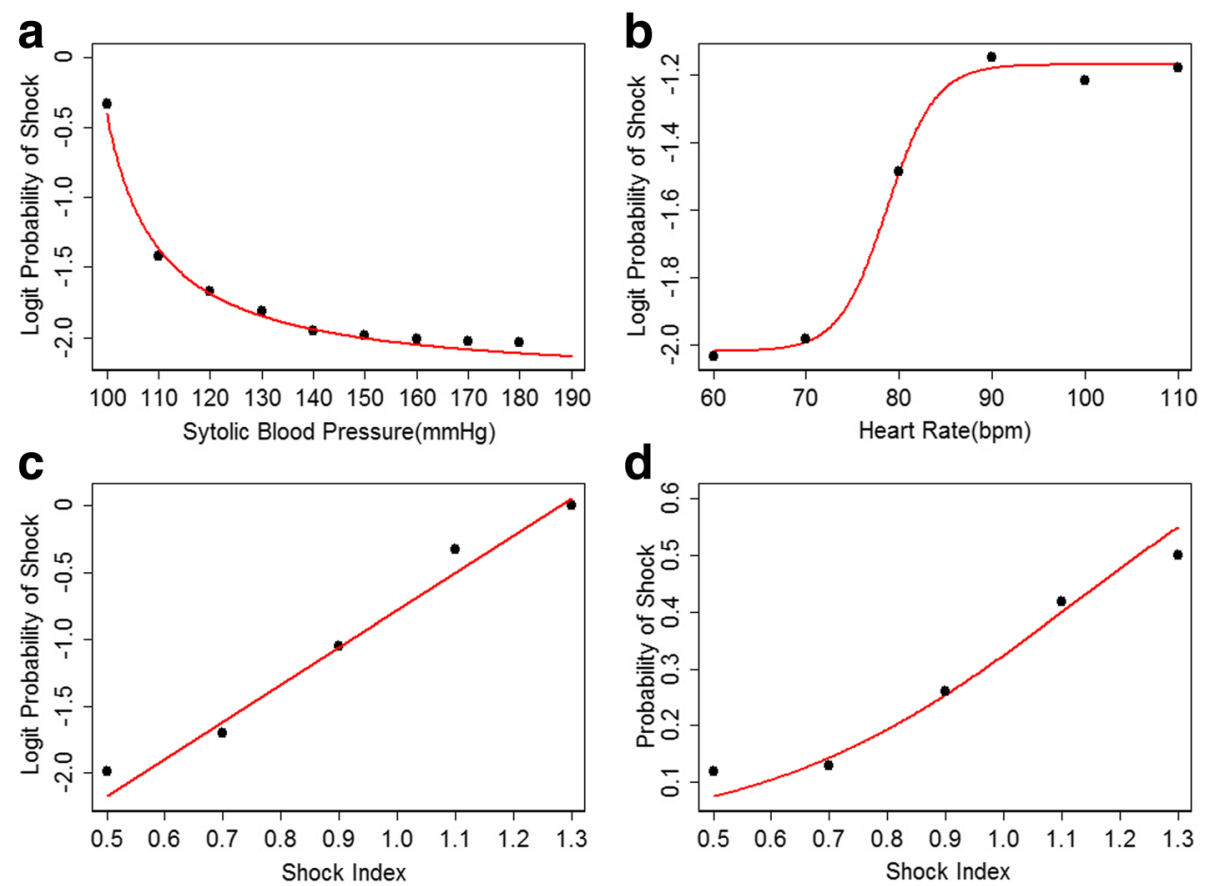

Fig. 1 (a) The logit probability of developing CS showed inverse proportional to the pre-procedural SBP. (b) The relationship between preprocedural HR and logit probability of developing CS formed a sigmoid curve. (c) The logit probability of developing CS was positive linear correlated to the SI. (d) The relationship between probability of developing CS and SI was fitted into a logistic function. The curve shown in the graph was just at the rapid descending part of the logistic curve, which was very close to a line. SBP: systolic blood pressure; HR: heart rate; SI: shock index; CS: cardiogenic shock

Developed Shock Group $(\mathrm{P}<0.001)$, while other medication was no different between two groups (Table 1).

\section{Identification of relevant risk factors}

In the analysis series, 72 patients were subjected to the CS during primary PCI. We took CS as dependent variable, the following factors as independent variables: age, sex category, pre-procedural SBP and pre-procedural HR, Killips classification, total ischemic duration, multiple vessel disease, extensive anterior MI, IRA, renal function, prior related history including hypertension, diabetes, dyslipidemia, MI, stroke and smoking habit. On univariate analysis, pre-procedural SBP and pre-procedural HR, Killips classification were the significant variables. Prior history of hypertension had a trend toward to statistical significance (Table 2).

In multivariate analysis, the above statistical significant variables together with some clinical significant variables including age, total ischemic duration, multiple vessel disease were set in the multivariate regression analysis. Table 3 showed the pre-procedural SBP, pre-procedural $\mathrm{HR}$ and Killips classification were the independent predictors. Hosmer-Lemeshow test demonstrated the model was well fitted $\left(\chi^{2}=6.43, P=0.599\right)$.

\section{Model fit of SI}

The regression model revealed the risk of developing CS was positively correlated with pre-procedural HR and negatively correlated with pre-procedural SBP. Furthermore, the scatter plot showed the relationship between logit probability of shock and pre-procedural SBP was nonlinear and a inverse proportional function was well fitted $(P<0.001$,adjust $\mathrm{R}$ square $=0.9904)$ (Fig. 1a). The relationship between logit probability of shock and pre-procedural HR was also nonlinear and a logistic function was fitted $(P<0.001$, adjust $\mathrm{R}$ square $=0.9973$ ) (Fig. 1b). SI was formulated as the ratio of pre-procedural $\mathrm{HR}$ to pre-procedural SBP. The logit probability of shock was positively linear correlated with SI $(\mathrm{P}<0.001$, adjust $\mathrm{R}$ square $=0.9549)$. The

Table 4 Multivariate regression analysis for shock index

\begin{tabular}{lllll}
\hline Variables & OR & SE & $P$ value & $95 \%$ Cl \\
\hline $\begin{array}{l}\text { Shock index (per 0.1 change) } \\
\text { Killips classification }\end{array}$ & 1.93 & 0.16 & $<0.01$ & {$\left[\begin{array}{lll}1.64 & 2.28\end{array}\right]$} \\
$\quad$ Killips $=2$ vs $=1$ & 2.21 & 0.69 & 0.01 & {$\left[\begin{array}{lll}1.21 & 4.06\end{array}\right]$} \\
Killips $=3$ vs $=1$ & 5.94 & 3.92 & 0.01 & {$\left[\begin{array}{lll}1.63 & 21.7\end{array}\right]$} \\
Shock index * Killips & & & $>0.05^{\#}$ & \\
\hline
\end{tabular}

$\# p>0.05$ indicated there was no significant interaction between shock index and Killips classification in the multivariate regression analysis 


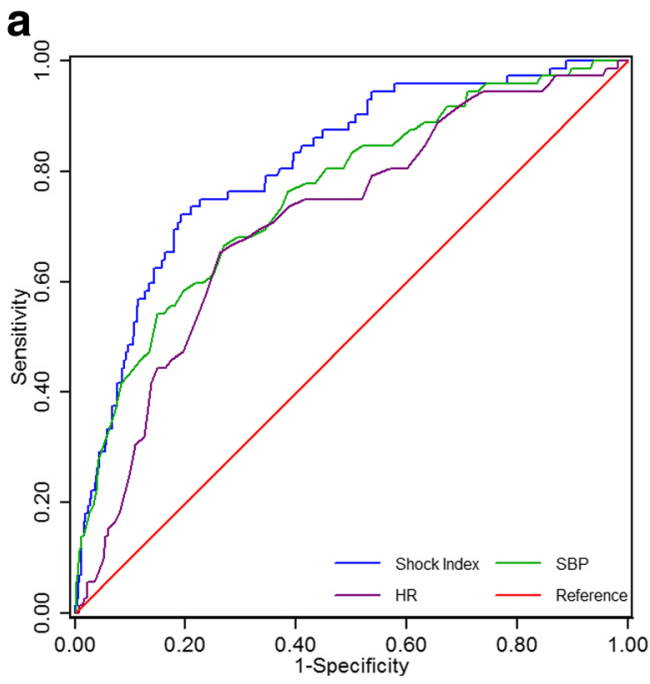

b

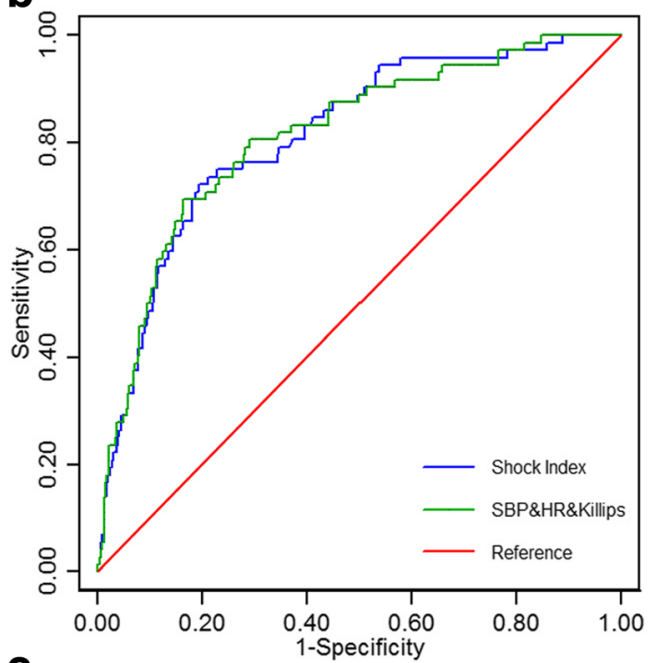

C

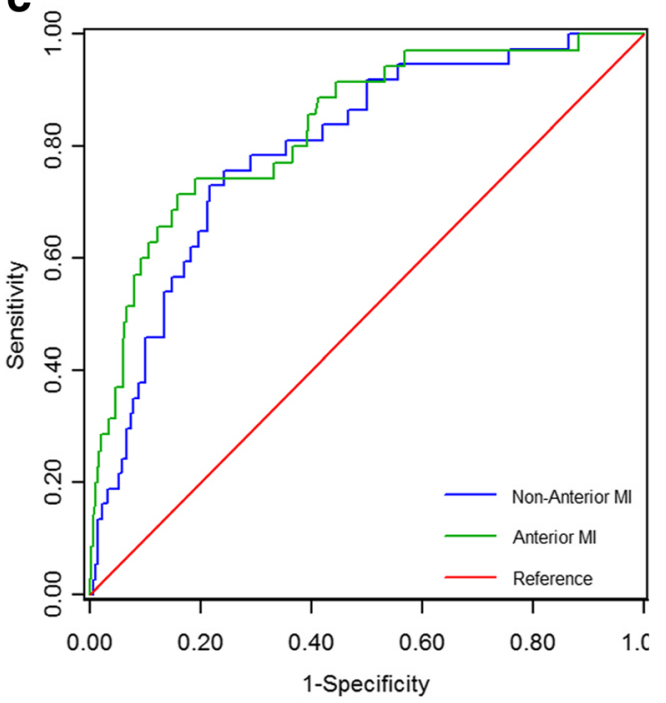

Fig. 2 (a) SI had a better diagnostic capability than pre-procedural SBP or pre-procedural HR alone. (b) The diagnostic capability of SI was similar to that of the combination of pre-procedural SBP and pre-procedural HR and Killips classification. (c) The diagnostic capability of SI had no difference between non-anterior MI subgroup and anterior MI subgroup. Sl: shock index; SBP: systolic blood pressure; HR: heart rate; Ml: myocardial infarction

relationship between probability of shock and SI was located at the rapid rise part of a sigmoid curve and the logistic function was well fitted $(\mathrm{P}<0.001$, adjust $\mathrm{R}$ square $=$ 0.9898) (Fig. 1c and d). Regression analysis demonstrated that SI was a significant independent predictor (Hosmer-Lemeshow $X^{2}=8.12, P=0.42$ )(Table 4). However, there was no interplay between SI and Killips classification no matter in CS cohort, non-CS cohort or global cohort. That meant Killips classification was not able to further promote the discriminability of SI.

\section{Diagnostic capability assessment}

With the calibration of ROC analysis, the AUC of SI was significantly higher than that of pre-procedural $\mathrm{SBP}(0.8113$ vs $0.7582, P=0.04)$ and pre-procedural $\operatorname{HR}(0.8113$ vs $0.7111, P<0.001)$ respectively(Fig. 2a). The AUC of SI was similar to the AUC of combination of SBP, HR and Killips classification $(0.8133$ vs 0.8137, $P=0.97$ ) (Fig. 2b). Moreover, the AUC of SI in anterior MI patients was not significantly different from that in non-anterior MI patients $(0.8332$ vs 0.7944, $P=0.46$ )(Fig. 2c).

The diagnostic parameters were calculated at different cutoff of SI (Table 5). Of note, SI had a high specificity and low sensitivity because of the relatively low incidence of developing CS during pPCI. In other words, it was suitable for exclusion diagnosis. When the cutoff was between $0.90 \sim 0.95$, the accuracy were all above $85 \%$ and the negative predictive value were higher than $90 \%$. If the cutoff was set at 0.93 , the negative predictive value was as high as $95 \%$.

\section{Predictive capability validation of SI}

In the validation series, total 29 patients had undergone CS during primary PCI. Logistic regression analysis demonstrated that the odd ratio of SI (per 0.1 changes) for predicting this event was $1.94(95 \%$ CI: $1.54-2.46)$. Hosmer-Lemeshow test revealed a excellent model fit $\left(x^{2}=\right.$ 8.57, $P=0.38$ ). The ROC curve of SI was depicted in Fig. 3 . The AUC of this curve was 0.8245 (95\% CI: 0.7441-0.9048). The incidence of developing CS at different breakpoints was shown in Fig. 4. If the cutoff value was set at 0.93, the sensitivity, specificity, positive predictive value and negative predictive value was $48.3 \%, 94.4 \%, 53.8 \%$ and $93.2 \%$ respectively. The accuracy and Youden index was $88.9 \%$ and $42.7 \%$ respectively. 
Table 5 The diagnostic capability assessment of shock index

\begin{tabular}{lllllll}
\hline Cutoff & Sensitivity(\%) & Specificity(\%) & Youden index(\%) & Accuracy(\%) & Positive predictive value(\%) & Negative predictive value(\%) \\
\hline 0.90 & 31.9 & 93.7 & 25.6 & 86.6 & 39.7 & 91.4 \\
0.91 & 30.6 & 94.0 & 24.6 & 86.7 & 40.0 & 91.2 \\
0.92 & 29.2 & 94.9 & 24.1 & 87.4 & 42.9 & 91.2 \\
0.93 & 27.8 & 95.1 & 22.9 & 87.4 & 42.6 & 95.1 \\
0.94 & 26.4 & 95.3 & 21.7 & 87.4 & 42.2 & 90.9 \\
0.95 & 22.2 & 96.2 & 18.4 & 87.7 & 43.2 & 90.5 \\
\hline
\end{tabular}

\section{Discussion}

SI is a reliable predictor for early shock in different situation, such as trauma, infection, pulmonary embolism, which is usually set 0.9 as the threshold of elevation [14-18]. However, there are several other cutoff values in different studies $[17,19,20]$, which means the diagnostic capability of SI varies over different conditions. Theoretically, SI should be more sensitive in reflexing the pre-shock state because heart rate usually elevates before the systolic blood pressure goes down as a compensatory response. Surprisingly, the consequence in our data was beyond our expectation.

Pre-procedural SBP, pre-procedural HR and Killips classification have been identified independent predictors of developing CS during emergency reperfusion in the current study, which is consistent with the previous findings [21,22]. Further analysis showed the relationship of logit probability of CS with pre-procedural SBP and pre-procedural HR were both not linear. The scatter dots were fitted into an inverse proportional function in the former relationship and a logistic function in the latter relationship. Despite the monotone change could make SBP

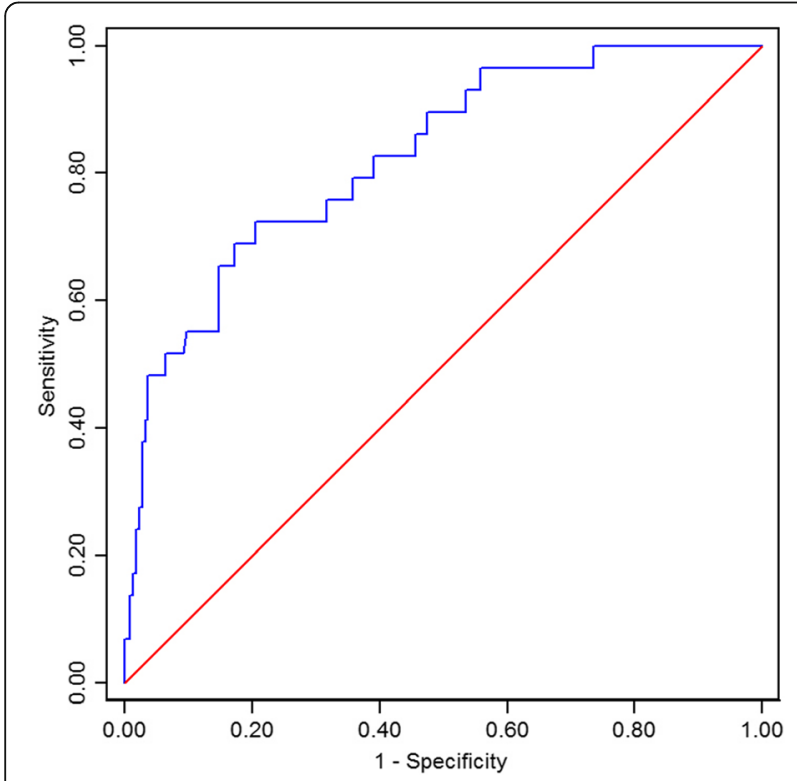

Fig. 3 The ROC curve of shock index in the validation series and HR predictors, there were flat parts in the both curves, which probably caused the makers less sensitive. On the contrary, SI had much better feature in this regard. The logit probability of shock was positive linear related to SI, which was an ideal relationship for the binary variables model. A recent study performed by Laust Obling et al. demonstrated that the odd ratio was 1.26 for per $10 \%$ change in the patients developing CS after leaving catheter laboratory [22]. In our data, the odd ratio was 1.93 for per $10 \%$ change. Of note, SI was not an independent predictor in Laust Obling's study, while it did in our study. The leading cause may be the ejection fraction (EF) was set in the regression analysis in the previous study. EF was highly associated with CS and probably masked the effect of SI. But EF was not available before pPCI in our setting.

ROC analysis proved that SI had a better diagnostic capability than either SBP or HR alone, while it had an equivalent diagnostic capability with the combination of SBP, HR and Killips classification. Killips classification could not further improve the diagnostic capability due to no interaction between SI and Killips classification. Therefore, we had reason using SI instead of the other independent predictors. The AUC of SI in the analysis series was highly close to that in the validation series, which implied SI was a reliable predictor. Nonetheless,

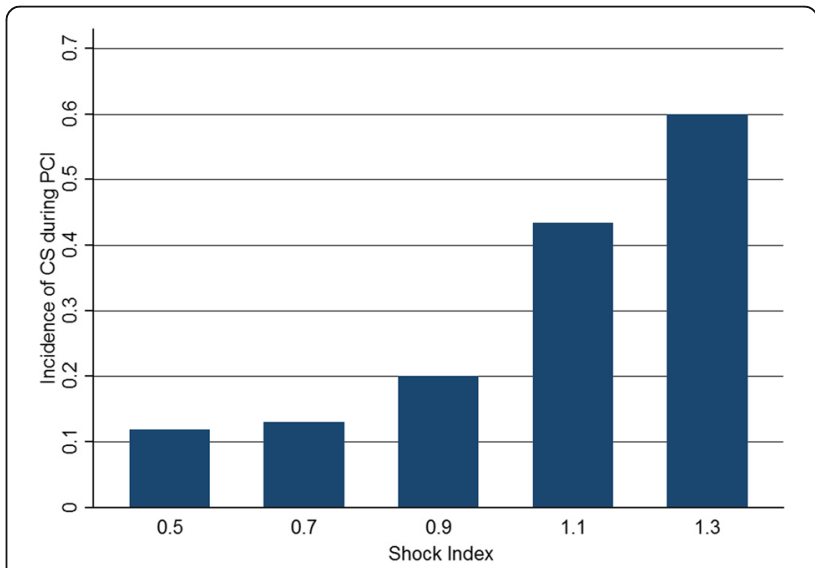

Fig. 4 The probability of CS developed during pPCI at different cutoff values of SI in the validation series. CS: cardiogenic shock; SI: shock index: pPCl: primary percutaneous coronary intervention 
SI had a high specificity and low sensitivity despite the predictive accuracy was above $85 \%$. The sensitivity and positive predictive value varied markedly, while the specificity and negative predictive value remained as high as about 95\%. The incidence of CS developed during pPCI in the study cohort influenced the sensitivity and positive predictive value. Generally speaking, the incidence of developing CS was not very high however. It meant SI was not a good index for confirmative diagnosis but a good index for exclusion of developing CS.

In the previous studies, the cutoff values were arbitrary and also varied over different settings. Nevertheless, SI norms change by age and gender just because the blood pressure and heart rate varies by age and gender $[18,23]$. SI declines about $0.01 \sim 0.02$ per every 5 years in male population and about $0.02 \sim 0.03$ per every 5 years in female population [18], which forms a slow declined curve. In other words, the same threshold might not be sensitive as to the aged population. Several studies have used age modified SI (age $\times \mathrm{SI}$ ) as a better predictor to offset the disadvantage of SI [24-26]. In our data, the breakpoint of SI was set at 0.93 as an ideal threshold for exclusion of developing CS. We did not use age modified SI just because age was not significant predictors. Moreover, we also attempted to modified SI using Killips classification to create a novel and better index, but failed in the end, which was mainly due to no interaction between SI and Killips classification.

\section{Conclusions}

According to the current study, SI had advantage in prediction of developing CS during pPCI for STEMI patients. It had an excellent negative predictive capability, but the positive predictive capability was not as so good.

\section{Limitations}

Firstly, the negative predictive value of SI had been proven approximate $95 \%$ by analysis and validation series. However, the difference of positive predictive value between analysis series and validation series was markedly due to a bit small sample size of validation series. Secondly, left main artery(LM) as IRA is a strong predictor of developing CS, which has been reported in previous study [22]. In our center, all the patients with LM as IRA had accepted prophylactic IABP support, which exclude these patients from current study. Therefore, we could not investigate the possible interaction of LM with SI. Thirdly, SI norms changes by age as aforementioned. We did not analyze the predictive value by age stratification due to age not being significant covariate by regression analysis. Maybe the age range in the data was not large enough or the analysis series sample was not large enough for SI to discriminate the diagnostic capability in different age groups. The last but not least, diabetes usually worsens the prognosis of the patients with acute myocardial infarction accompanied with multivessel disease [27, 28]. It may affect the anti-apoptotic properties of atherosclerotic plaques and reduce the mobilization of stem cells to repair the damaged myocardial tissue [29, 30]. However, in the current study, diabetes did not play an important role in developing CS during primary PCI. It may be considered that diabetes influences the long-term prognosis rather than instant consequence of acute myocardial infarction. Moreover, incretin, a novel antidiabetic drug, has been identified a protective effect on the cardiovascular events. It could improve the cardiovascular prognosis of diabetic patients by pleiotropic effect $[27,28]$. In our patient cohort, we did not have the detail percentage of the patients who had accepted incretin therapy, which preclude us to evaluate whether incretin therapy could protect the patients against developing CS during primary PCI.

\begin{abstract}
Abbreviations
ACEl: Angiotensin converting enzyme inhibitor; ACS: Acute coronary syndrome; ARB: Angiotensin receptor blocker; AUC: Area under curve; CABG: Coronary artery bypass graft; CS: Cardiogenic shock; HR: Heart rate; IABP: Intra-aortic balloon counterpulsation; IRA: Infarct-related artery; LAD: Left anterior descending branch; LCX: Left circumflex branchor; MACE: Major adverse cardiac events; MI: Myocardial infarction; OM: Obtuse marginal branchas; PDA: Posterior descending artery; PL: Posterior branch of left venticule; $\mathrm{PPCl}$ : Primary percutaneous coronary intervention; RCA: Right coronary artery; ROC: Receiver-operating characteristics; SBP: Systolic blood pressure; SI: shock index; STEMI: ST segment elevation myocardial infarction
\end{abstract}

\section{Fundings}

This study was supported by the National Natural Science Foundation of China (No. 81700392) and the Municipal Medical Science Technology Development Foundation of Nanjing(No. YKK17085).

\section{Availability of data and materials}

The datasets generated and/or analyzed during the current study are not publicly available because the information and data of the study population were extracted from Hospital Information System and were recorded manually in EXCEL to form our private database. But the data are available from the corresponding author on reasonable request.

\section{Authors' contributions}

ZHW: Conception and design, manuscript writing, data analysis and interpretation. JB: manuscript writing, accountable for all aspects of the work in ensuring that questions related to the accuracy or integrity of any part of the work are appropriately investigated and resolved. QD: data analysis and interpretation. HW: data acquisition and graph making. SHQ: data acquisition and management. BX: manuscript revising for important intellectual content. LW: manuscript and data revising, approval of the version to be published. All the authors have read and approved the manuscript and ensure that this is the case.

Ethics approval and consent to participate

not applicable.

Consent for publication

not applicable.

Competing interests

The authors of this article have no competing interest. 


\section{Publisher's Note}

Springer Nature remains neutral with regard to jurisdictional claims in published maps and institutional affiliations.

Received: 26 June 2018 Accepted: 23 September 2018

Published online: 01 October 2018

\section{References}

1. O'Gara PT, Kushner FG, Ascheim DD, Casey DE Jr, Chung MK, de Lemos JA, et al. 2013 ACCF/AHA guideline for the management of ST-elevation myocardial infarction: a report of the American College of Cardiology Foundation/American Heart Association task force on practice guidelines. Circulation. 2013;127:e362-425.

2. Yellon DM, Hausenloy DJ. Myocardial reperfusion injury. N Engl J Med. 2007; 357:1121-35.

3. Frohlich GM, Meier P, White SK, Yellon DM, Hausenloy DJ. Myocardial reperfusion injury: looking beyond primary PCI. Eur Heart J. 2013;34:171422.

4. Goldberg RJ, Spencer FA, Gore JM, Lessard D, Yarzebski J. Thirty-year trends (1975 to 2005) in the magnitude of, management of, and hospital death rates associated with cardiogenic shock in patients with acute myocardial infarction: a population-based perspective. Circulation. 2009;119:1211-9.

5. De Luca L, Olivari Z, Farina A, Gonzini L, Lucci D, Di Chiara A, et al. Temporal trends in the epidemiology, management, and outcome of patients with cardiogenic shock complicating acute coronary syndromes. Eur J Heart Fail. 2015;17:1124-32

6. Harjola VP, Lassus J, Sionis A, Kober L, Tarvasmaki T, Spinar J, et al. Clinical picture and risk prediction of short-term mortality in cardiogenic shock. Eur J Heart Fail. 2015;17:501-9.

7. Babaev A, Frederick PD, Pasta DJ, Every N, Sichrovsky T, Hochman JS. Trends in management and outcomes of patients with acute myocardial infarction complicated by cardiogenic shock. JAMA. 2005;294:448-54.

8. Spyridopoulos I, Noman A, Ahmed JM, Das R, Edwards R, Purcell I, et al. Shock-index as a novel predictor of long-term outcome following primary percutaneous coronary intervention. Eur Heart J Acute Cardiovasc Care. 2015:4:270-7.

9. Hemradj W, Ottervanger JP, de Boer MJ, Suryapranata H. Shock index more sensitive than cardiogenic shock in ST-elevation myocardial infarction treated by primary percutaneous coronary intervention. Circ J. 2017:81:199-205.

10. Abe N, Miura T, Miyashita Y, Hashizume N, Ebisawa S, Motoki H, et al. Longterm prognostic implications of the admission shock index in patients with acute myocardial infarction who received percutaneous coronary intervention. Angiology. 2017;68:339-45.

11. Yu T, Tian C, Song J, He D, Sun Z. Derivation and validation of shock index as a parameter for predicting long-term prognosis in patients with acute coronary syndrome. Sci Rep. 2017;7:11929.

12. Thygesen K, Alpert JS, Jaffe AS, Simoons ML, Chaitman BR, White HD, et al. Third universal definition of myocardial infarction. Circulation. 2012;126: 2020-35.

13. Thiele H, Zeymer U, Neumann FJ, Ferenc M, Olbrich HG, Hausleiter J, et al. Intraaortic balloon support for myocardial infarction with cardiogenic shock. N Engl J Med. 2012;367:1287-96.

14. McMahon CG, Kenny R, Bennett K, Little R, Kirkman E. The effect of acute traumatic brain injury on the performance of shock index. J Trauma. 2010; 69:1169-75.

15. Bircan A, Karadeniz N, Ozden A, Cakir M, Varol E, Oyar O, et al. A simple clinical model composed of ECG, shock index, and arterial blood gas analysis for predicting severe pulmonary embolism. Clin Appl Thromb Hemost. 2011;17:188-96

16. Birkhahn RH, Gaeta TJ, Terry D, Bove JJ, Tloczkowski J. Shock index in diagnosing early acute hypovolemia. Am J Emerg Med. 2005;23:323-6.

17. Sankaran P, Kamath AV, Tariq SM, Ruffell H, Smith AC, Prentice $P$, et al. Are shock index and adjusted shock index useful in predicting mortality and length of stay in community-acquired pneumonia? Eur J Intern Med. 2011; 22:282-5.

18. Rappaport LD, Deakyne S, Carcillo JA, McFann K, Sills MR. Age- and sexspecific normal values for shock index in National Health and nutrition examination survey 1999-2008 for ages 8 years and older. Am J Emerg Med. 2013;31:838-42.
19. Keller AS, Kirkland LL, Rajasekaran SY, Cha S, Rady MY, Huddleston JM. Unplanned transfers to the intensive care unit: the role of the shock index. J Hosp Med. 2010;5:460-5

20. Guyette F, Suffoletto B, Castillo JL, Quintero J, Callaway C, Puyana JC. Prehospital serum lactate as a predictor of outcomes in trauma patients: a retrospective observational study. J Trauma. 2011;70:782-6.

21. De Luca G, Savonitto S, Greco C, Parodi G, Dajelli Ermolli NC, Silva C, et al. Cardiogenic shock developing in the coronary care unit in patients with STelevation myocardial infarction. J Cardiovasc Med (Hagerstown). 2008;9:1023-9.

22. Obling L, Frydland M, Hansen R, Moller-Helgestad OK, Lindholm MG, Holmvang $L$, et al. Risk factors of late cardiogenic shock and mortality in STsegment elevation myocardial infarction patients. Eur Heart J Acute Cardiovasc Care. 2018;7:7-15.

23. Park MK. Blood pressure tables. Pediatrics. 2005;115:826-7 author reply 7.

24. Yu T, Tian C, Song J, He D, Sun Z. Age shock index is superior to shock index and modified shock index for predicting long-term prognosis in acute myocardial infarction. Shock. 2017:48:545-50.

25. Zarzaur BL, Croce MA, Fischer PE, Magnotti LJ, Fabian TC. New vitals after injury: shock index for the young and age $x$ shock index for the old. I Surg Res. 2008;147:229-36.

26. Torabi M, Moeinaddini S, Mirafzal A, Rastegari A, Sadeghkhani N. Shock index modified shock index, and age shock index for prediction of mortality in emergency severity index level 3. Am J Emerg Med. 2016;34:2079-83.

27. Marfella R, Sardu C, Balestrieri ML, Siniscalchi M, Minicucci F, Signoriello G, et al. Effects of incretin treatment on cardiovascular outcomes in diabetic STEMI-patients with culprit obstructive and multivessel non obstructivecoronary-stenosis. Diabetol Metab Syndr. 2018;10:1

28. Marfella R, Sardu C, Calabro P, Siniscalchi M, Minicucci F, Signoriello G, et al. Non-ST-elevation myocardial infarction outcomes in patients with type 2 diabetes with non-obstructive coronary artery stenosis: effects of incretin treatment. Diabetes Obes Metab. 2018;20:723-9.

29. Balestrieri ML, Rizzo MR, Barbieri M, Paolisso P, D'Onofrio N, Giovane A, et al Sirtuin 6 expression and inflammatory activity in diabetic atherosclerotic plaques: effects of incretin treatment. Diabetes. 2015;64:1395-406.

30. Marfella R, Rizzo MR, Siniscalchi M, Paolisso P, Barbieri M, Sardu C, et al. Periprocedural tight glycemic control during early percutaneous coronary intervention up-regulates endothelial progenitor cell level and differentiation during acute ST-elevation myocardial infarction: effects on myocardial salvage. Int J Cardiol. 2013;168:3954-62.

\section{Ready to submit your research? Choose BMC and benefit from:}

- fast, convenient online submission

- thorough peer review by experienced researchers in your field

- rapid publication on acceptance

- support for research data, including large and complex data types

- gold Open Access which fosters wider collaboration and increased citations

- maximum visibility for your research: over $100 \mathrm{M}$ website views per year

At $\mathrm{BMC}$, research is always in progress.

Learn more biomedcentral.com/submission 